\title{
Rethinking Development Strategies after the Financial Crisis
}

\section{Making the Case for Policy Space, Country Studies and International Comparisons}

\section{Motivation}

- The recent economic trends and the challenges posed by the global crisis reinforce the importance of implementing strategies for development as opposed to leaving the economy to market forces.

- Countries need a strategic compass for long-run economic development, either explicitly or implicitly. Arguably, the slow-growth periods endured by several countries (the "lost decades") allow inferring which policies should be avoided.

- The authors of these two edited books share the notion that developing countries can and should learn more from each other, as well as from their own past experience. It is important to look at comparisons between developing countries, including both success and failure stories.

CONTRIBUTION OF DEVELOPING AND TRANSITION ECONOMIES TO GLOBAL OUTPUT,1970-2013

(Per cent of global GDP in current dollars)

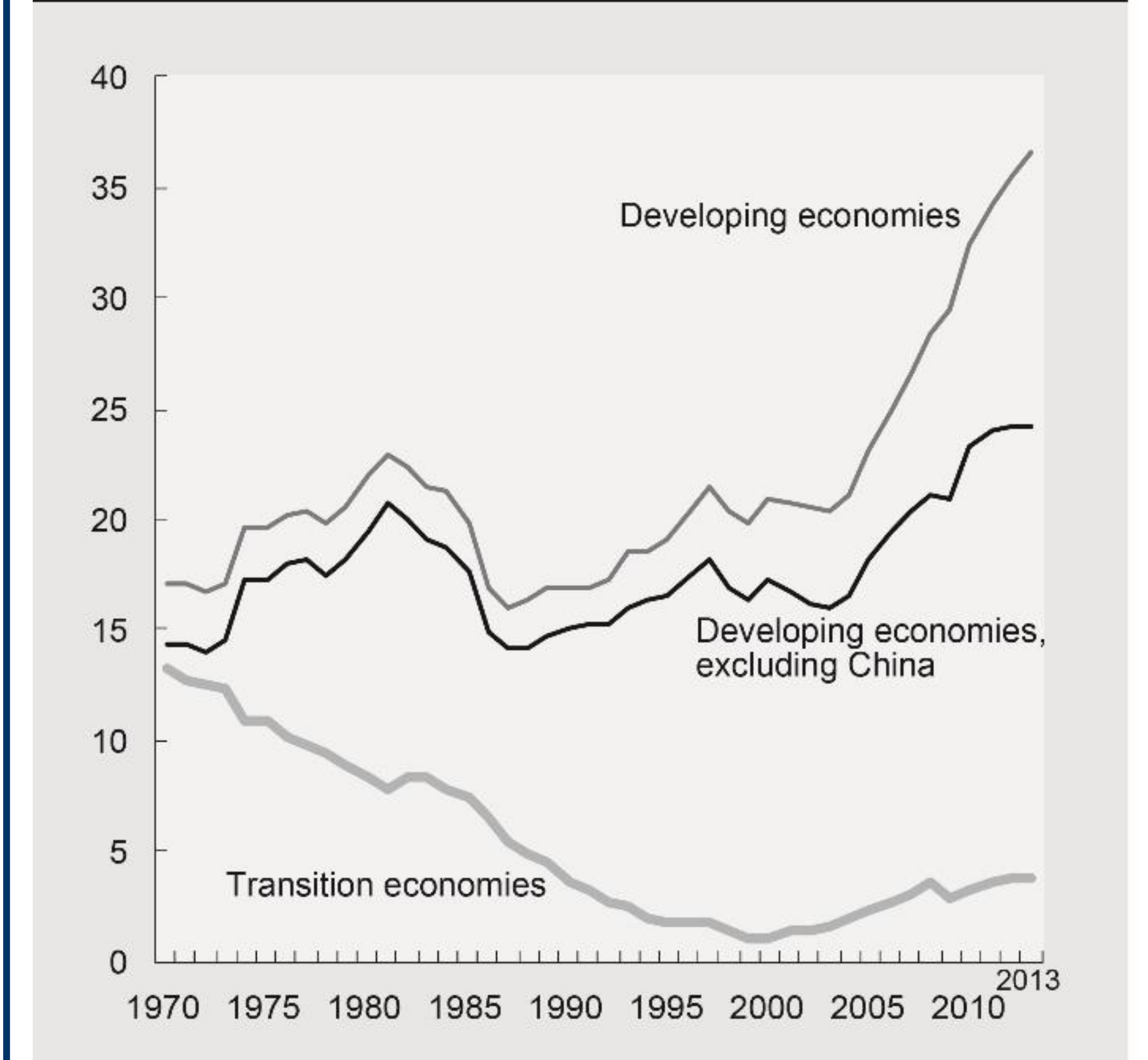

Source: UNCTAD secretariat calculations, based on UN-DESA, National Accounts Main Aggregates database.

\section{Issues and Countries Covered}

- In the first volume, the general issues that all developing countries need to handle are discussed. Among these are:

- Reacting to the global financial crisis.

- Assessing different development strategies.

- Analyzing the global development architecture.

- Understanding the middle-income trap.

- In the second volume, four countries are selected based upon their role within the developing world and the current discourses on development: Brazil, Chile, China and India.
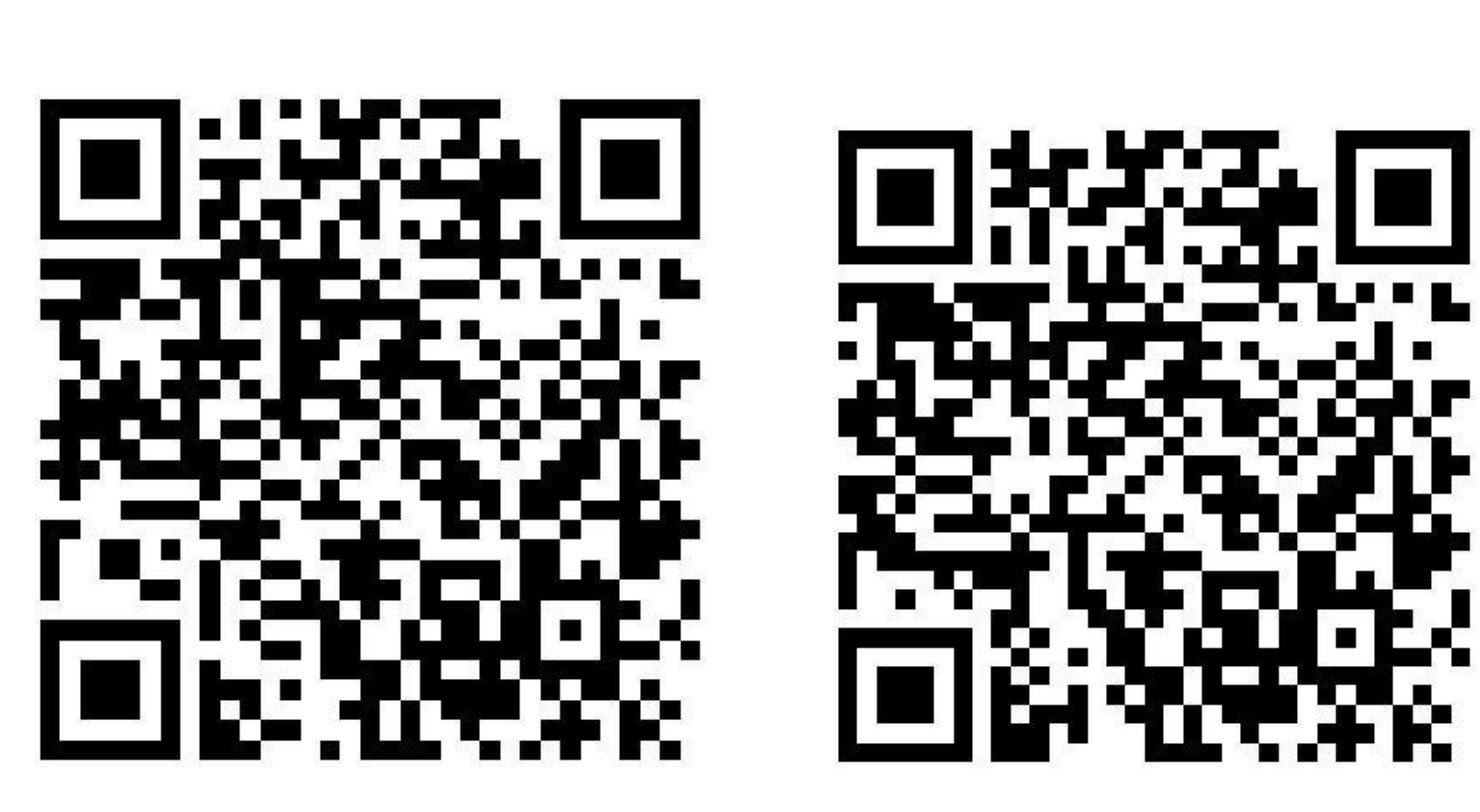

Further information

Cooperation partners:
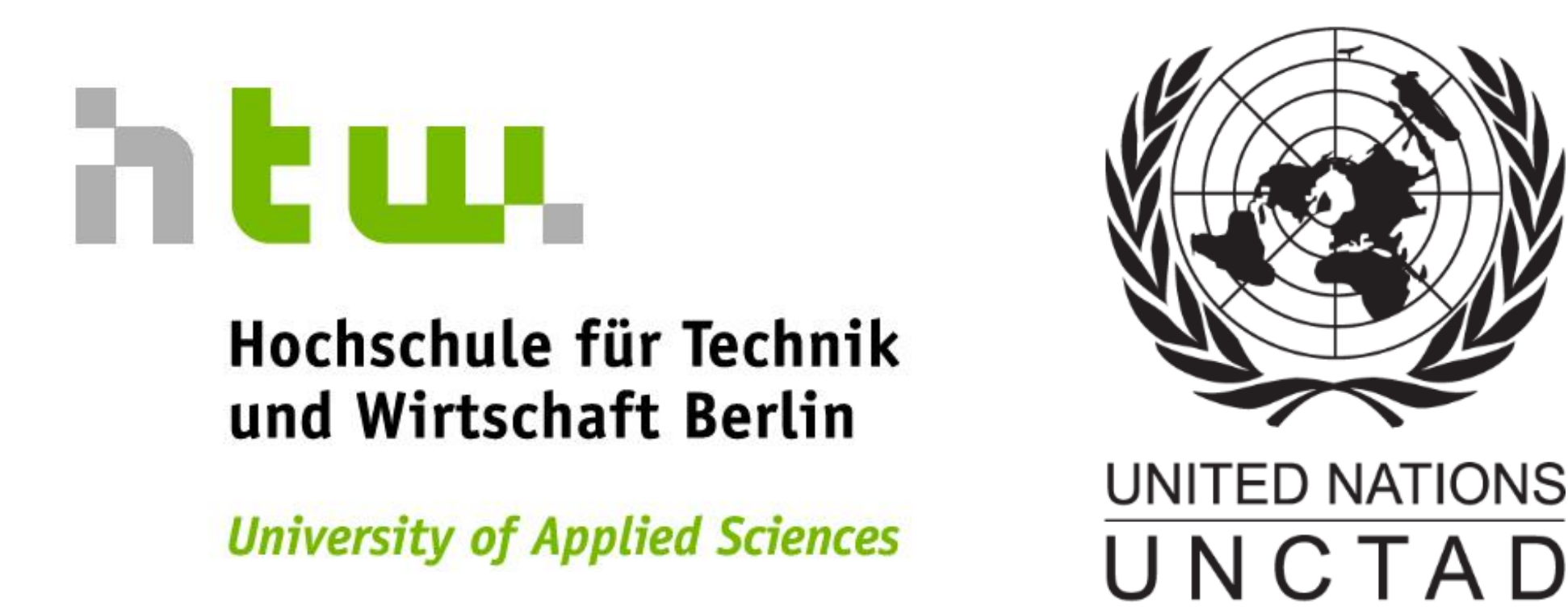